\title{
Changes in vitamin $D$ after gastrectomy
}

\author{
Yasushi Rino ${ }^{1}$, Yuji Yamamoto ${ }^{2}$, Nobuyuki Wada ${ }^{1}$, Norio Yukawa ${ }^{1}$, Hitoshi Murakami ${ }^{1}$, Hiroshi Tamagawa ${ }^{1}$, \\ Takanobu Yamada ${ }^{3}$, Takashi Ohshima ${ }^{3}$, Munetaka Masuda ${ }^{1}$, and Toshio Imada ${ }^{4}$ \\ ${ }^{1}$ Department of Surgery, Yokohama City University School of Medicine, 3-9 Fukuura, Kanazawa-ku, Yokohama 236-0004, Japan \\ ${ }^{2}$ Department of Surgery, Kanagawa Prefectural Ashigara-kami Hospital, Kanagawa, Japan \\ ${ }^{3}$ Department of Gastroenterology, Yokohama City University Medical Center, Yokohama, Japan \\ ${ }^{4}$ Yokohama City University Hospital, Yokohama, Japan
}

\begin{abstract}
Background. We previously reported that the administration of $1 \alpha$ hydroxy vitamin $\mathrm{D3}$ was effective for treating postgastrectomy bone disorders. Accordingly, we performed the present study to obtain evidence supporting the effectiveness of $1 \alpha$ hydroxy vitamin $\mathrm{D3}$ in post-gastrectomy patients.

Methods. The study involved 22 outpatients who had undergone gastrectomy for gastric cancer and had not been treated with $1 \alpha$ hydroxy vitamin D3 or calcium. They comprised 17 men and 5 women, with a mean age of 61.9 years. Laboratory tests were performed to examine the following parameters: $1,25(\mathrm{OH})_{2}$ vitamin D3; $25(\mathrm{OH})$ vitamin $\mathrm{D3} ; 24,25(\mathrm{OH})_{2}$ vitamin D3; ionized calcium; calcium; phosphorus; alkaline phosphatase; $\mathrm{N}$-parathyroid hormone; and osteocalcin.

Results. The level of $1,25(\mathrm{OH})_{2}$ vitamin $\mathrm{D3}$, the most active of the vitamin D metabolites, was found to be normal in all of the patients. In contrast, the level of $25(\mathrm{OH})$ vitamin D3, which shows weak activity, was below the normal range in 7 of the 22 patients $(31.8 \%)$. The mean serum level of $25(\mathrm{OH})$ vitamin D3 was significantly lower in patients at 1 year or more postoperatively than the level in those at less than 1 year postoperatively $(P=0.041)$, as well as being significantly lower in patients who had received total gastrectomy than in patients who underwent other gastrectomy procedures. The level of $24,25(\mathrm{OH})_{2}$ vitamin $\mathrm{D3}$, a metabolite of $25(\mathrm{OH})$ vitamin D3 that shows weak activity, was below the normal range in 19 of the 22 patients $(86.4 \%)$. On multivariate analyses, factors associated with the change in vitamin $D$ metabolites did not remain.

Conclusion. The patients showed a decrease of $25(\mathrm{OH})$ vitamin D3 and 24,25(OH) $)_{2}$ vitamin D3, which are metabolites that show weak activity. This suggests that a homeostatic response maintains the normal level of $1,25(\mathrm{OH})_{2}$ vitamin $\mathrm{D3}$, which is important for calcium regulation. Thus, it was suggested that gastrectomy had a moderate influence on the metabolism of vitamin D. However we could not detect any factor associated with the decrease of $25(\mathrm{OH})$ vitamin $\mathrm{D3}$ and 24,25(OH), vitamin D3.
\end{abstract}

Offprint requests to: Y. Rino

Received: April 19, 2007 / Accepted: October 11, 2007
Key words Gastrectomy · Bone disorder · Vitamin D

\section{Introduction}

The occurrence of post-gastrectomy bone disorders has been explained in terms of impaired calcium (Ca) absorption, reduced milk intake, and decreased food intake [1]. As is done for patients with ordinary osteoporosis, $\mathrm{Ca}$ and vitamin supplements are administered to treat patients with post-gastrectomy bone disorders $[2,3]$. As drugs that inhibit bone resorption by osteoclasts have also been developed recently $[4,5]$, a variety of treatment options is now available to manage bone disorders arising after gastrectomy for gastric cancer. It has been reported that the serum level of $25(\mathrm{OH})$ vitamin D3 is decreased and the serum level of $1,25(\mathrm{OH})_{2}$ vitamin D3 is increased in gastrectomy patients [6]. However, to the best of our knowledge, there have been no reports about changes in vitamin D3 (VD) metabolites. We previously reported that the administration of $1 \alpha$ hydroxy vitamin D3 $(1 \alpha)$ was effective for treating post-gastrectomy bone disorders [7]. However, it has also been reported that the administration of such VD preparations has an adverse influence on bone metabolism [8]. Against this background, we performed the present study to obtain evidence to support the administration of $1 \alpha$ for treating post-gastrectomy bone disorders.

\section{Patients and methods}

The study involved 22 outpatients who had undergone gastrectomy for gastric cancer and had not been treated with $1 \alpha$ or $\mathrm{Ca}$, and who gave informed consent for blood sampling for biochemistry tests. They comprised 17 men and 5 women, with a mean age of 61.9 years (range, 
Table 1. Patient characteristics

\begin{tabular}{lccc}
\hline Characteristic & Normal range & Mean \pm SD (range) & No. of patients $(n)$ \\
\hline $\begin{array}{l}\text { Male/female ratio } \\
\text { Age (years) }\end{array}$ & & $61.9 \pm 12.7(35-85)$ \\
Surgical procedure & TG/B1/B2 & $3.4 \pm 3.7(0.2-13.8)$ \\
Postoperative period (years) & & $50.0 \pm 13.0(21-75)$ \\
1,25(OH) VD $(\mathrm{ng} / \mathrm{ml})$ & $20-76$ & $13.5 \pm 5.1(7-24)$ \\
$25(\mathrm{OH}) \mathrm{VD}(\mathrm{ng} / \mathrm{ml})$ & $10-55$ & $1.60 \pm 1.13(0.7-5.1)$ \\
24,25(OH)2VD $(\mathrm{ng} / \mathrm{ml})$ & $1.8-3.8$ & $2.51 \pm 0.10(2.30-2.70)$ \\
Ionized calcium $(\mathrm{mEq} / \mathrm{l})$ & $2.21-2.52$ & $4.58 \pm 0.20(4.05-4.90)$ \\
Calcium $(\mathrm{mEq} / \mathrm{l})$ & $4.25-4.90$ & $1.88 \pm 0.32(1.04-2.38)$ \\
$\mathrm{P}(\mathrm{mEq} / \mathrm{l})$ & $1.45-2.49$ & $243.1 \pm 109.5(139-650)$ \\
ALP $(\mathrm{mU} / \mathrm{ml})$ & $79-224$ & $293.2 \pm 173.6(156-770)$ \\
$\mathrm{N}-\mathrm{PTH}(\mathrm{pg} / \mathrm{ml})$ & $230-630$ & $10.1 \pm 2.9(7.3-18.0)$ \\
Osteocalcin $(\mathrm{ng} / \mathrm{ml})$ & $1.5-6.5$ &
\end{tabular}

35-85 years). Four patients had been treated by total gastrectomy, 13 had undergone subtotal Billroth-I gastrectomy, and 5 had received subtotal Billroth-II gastrectomy. The postoperative period until the beginning of the study ranged from 2 months to 14 years (Table 1 ). Because of the VD pathway, we performed laboratory tests to examine the following parameters: $1,25(\mathrm{OH})_{2} \mathrm{VD}$ (normal range, 20-76 ng/ml); 25(OH)VD (normal range, $10-55 \mathrm{ng} / \mathrm{ml}$ ); 24,25(OH) 2 VD (normal range, $1.8-3.8 \mathrm{ng} / \mathrm{ml}$ ); ionized $\mathrm{Ca}$ (normal range, 2.21-2.52 mEq/l); Ca (normal range, $4.25-4.90 \mathrm{mEq} / \mathrm{l}$ ); phosphorus (P; normal range, $1.45-2.49 \mathrm{mEq} / \mathrm{l})$; alkaline phosphatase (ALP; normal range, $79-224 \mathrm{mU} /$ $\mathrm{ml}$ ); N-parathyroid hormone (N-PTH; normal range, $230-630 \mathrm{pg} / \mathrm{ml}$ ); and osteocalcin (normal range, $1.5-6.5 \mathrm{ng} / \mathrm{ml})$.

Statistical analyses were performed using the $\chi^{2}$ test, Student's $t$-test, and multivariate analysis. Statistical significance was defined as $P<0.05$.

\section{Results}

The level of $1,25(\mathrm{OH})_{2} \mathrm{VD}$, the most active of the VD metabolites, was found to be normal in all of the patients. That is, serum $1,25(\mathrm{OH})_{2} \mathrm{VD}$ did not decrease over time after gastrectomy and was not affected by the type of gastrectomy procedure. In contrast, the level of 25(OH)VD, which shows weak activity, was below the normal range in 7 of the 22 patients $(32 \%)$. One of the 6 patients $(17 \%)$ tested at less than 1 year postoperatively had a $25(\mathrm{OH}) \mathrm{VD}$ below the normal range, versus 6 of the 16 patients $(38 \%)$ tested at 1 year or more postoperatively, although the difference between the two groups was not statistically significant (Fig. 1). However, the mean serum level of $25(\mathrm{OH}) \mathrm{VD}$ was significantly lower in patients at 1 year or more postoperatively than in those at less than 1 year postoperatively $(P=0.041)$, as well as being significantly lower in patients

\section{$1,25(\mathrm{OH})_{2} \mathrm{VD} \quad 25(\mathrm{OH}) \mathrm{VD} \quad 24,25(\mathrm{OH}) 2 \mathrm{VD}$}

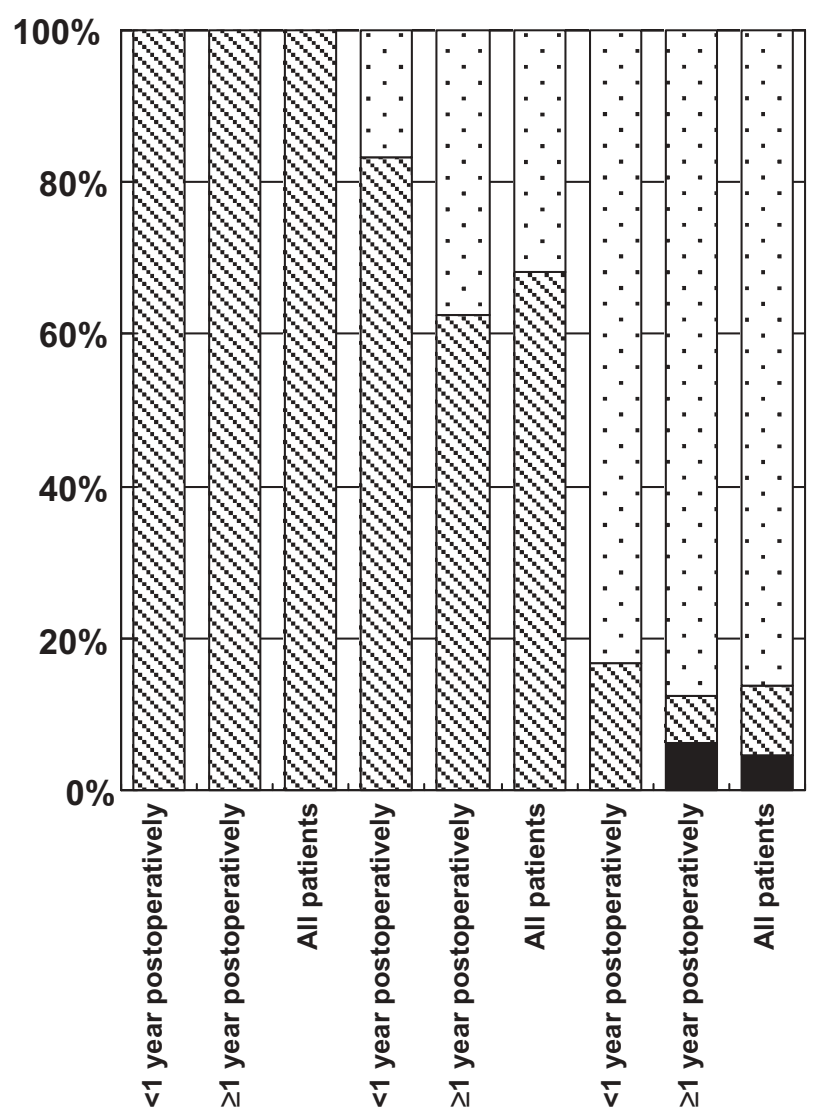

Fig. 1. Percentages of patients with low, normal, and high serum levels of $1,25(\mathrm{OH})_{2}$ vitamin D3 (VD), 25(OH)VD, and $24,25(\mathrm{OH})_{2} \mathrm{VD}$. The serum level of $1,25(\mathrm{OH})_{2} \mathrm{VD}$ was normal in all of the patients. The serum level of $25(\mathrm{OH}) \mathrm{VD}$ was lower than the normal range in $32 \%$ of the patients, including $17 \%$ of those at less than 1 year postoperatively and $38 \%$ of those at 1 year or more postoperatively. There was no significant difference between these two subgroups. The serum level of $24,25(\mathrm{OH})_{2} \mathrm{VD}$ was lower than the normal range in $86 \%$ of the patients, including $83 \%$ of those at less than 1 year postoperatively and $88 \%$ of those at 1 year or more postoperatively. White dotted bars, low level; striped bars, normal level; black bars, high level 
Table 2. Relation between vitamin D and surgery

\begin{tabular}{|c|c|c|c|c|c|c|}
\hline $\begin{array}{l}\text { Clinical } \\
\text { factors }\end{array}$ & $25(\mathrm{OH}) \mathrm{VD}$ & $24,25(\mathrm{OH})_{2} \mathrm{VD}$ & $1,25(\mathrm{OH})_{2} \mathrm{VD}$ & $1,25(\mathrm{OH})_{2} \mathrm{VD} / 25(\mathrm{OH}) \mathrm{VD}$ & $\begin{array}{l}1,25(\mathrm{OH})_{2} \mathrm{VD} / \\
24,25(\mathrm{OH})_{2} \mathrm{VD}\end{array}$ & $\begin{array}{c}25(\mathrm{OH}) \mathrm{VD} / \\
24,25(\mathrm{OH})_{2} \mathrm{VD}\end{array}$ \\
\hline \multicolumn{7}{|c|}{ Surgical procedure } \\
\hline $\mathrm{TG}^{\circ}$ & $8.3 \pm 1.3$ & $0.98 \pm 0.21$ & $51.8 \pm 9.2$ & $6.5 \pm 1.8$ & $63.5 \pm 25.1$ & $9.6 \pm 1.5$ \\
\hline \multirow[t]{2}{*}{ SG } & $14.6 \pm 4.9$ & $1.40 \pm 1.07$ & $49.6 \pm 13.9$ & $3.8 \pm 1.7$ & $48.2 \pm 16.5$ & $12.6 \pm 4.3$ \\
\hline & $P=0.019$ & NS & NS & $P=0.010$ & NS & NS \\
\hline \multicolumn{7}{|c|}{ Duodenal passage } \\
\hline Yes & $14.9 \pm 4.4$ & $1.20 \pm 0.57$ & $47.8 \pm 15.1$ & $3.5 \pm 1.5$ & $48.0 \pm 24.8$ & $13.7 \pm 4.1$ \\
\hline \multirow[t]{2}{*}{ No } & $11.3 \pm 5.4$ & $1.46 \pm 1.42$ & $53.2 \pm 9.1$ & $5.4 \pm 2.0$ & $55.4 \pm 29.5$ & $9.7 \pm 2.7$ \\
\hline & NS & NS & NS & $P=0.020$ & NS & $P=0.018$ \\
\hline \multicolumn{7}{|c|}{ Postoperative period (years) } \\
\hline$<1$ & $17.0 \pm 5.8$ & $1.92 \pm 1.61$ & $45.3 \pm 16.8$ & $2.9 \pm 1.4$ & $33.2 \pm 19.4$ & $11.6 \pm 5.3$ \\
\hline \multirow[t]{2}{*}{$>=1$} & $12.1 \pm 4.2$ & $1.08 \pm 0.53$ & $51.8 \pm 11.4$ & $4.8 \pm 1.9$ & $57.7 \pm 26.0$ & $12.2 \pm 3.7$ \\
\hline & $P=0.041$ & NS & NS & $P=0.045$ & NS & NS \\
\hline
\end{tabular}

who had received a total gastrectomy than in patients who had undergone the other gastrectomy procedures (Table 2). The level of $24,25(\mathrm{OH})_{2} \mathrm{VD}$, a metabolite of $25(\mathrm{OH}) \mathrm{VD}$ that shows weak activity, was below the normal range in 19 of the 22 patients (86\%). The level of $24,25(\mathrm{OH})_{2} \mathrm{VD}$ was below normal in 5 of the 6 patients $(83 \%)$ at less than 1 year postoperatively, versus 14 out of 16 patients (88\%) at 1 year or more. Although difference between the groups was not significant, one of the patients at 1 year or more postoperatively had a $24,25(\mathrm{OH})_{2}$ VD level above the normal range (Fig. 1). The mean $24,25(\mathrm{OH})_{2}$ VD level was lower, although not significantly so, in patients at 1 year or more postoperatively than in patients at less than 1 year postoperatively, as was the case for $25(\mathrm{OH}) \mathrm{VD}$. The mean $24,25(\mathrm{OH})_{2} \mathrm{VD}$ level was also lower, although not significantly so, in patients who had received a total gastrectomy (Table 2).

From a comparison of these three VD metabolites, the following results were obtained: the $1,25(\mathrm{OH})_{2} \mathrm{VD} /$ $25(\mathrm{OH}) \mathrm{VD}$ ratio was significantly higher after a total gastrectomy, after gastrectomy procedures avoiding the duodenal passage of food, and at 1 year or more postoperatively, while the $25(\mathrm{OH}) \mathrm{VD} / 24,25(\mathrm{OH})_{2} \mathrm{VD}$ ratio was significantly lower after gastrectomy procedures avoiding the duodenal passage of food (Table 2).

The ionized $\mathrm{Ca}$ level was above the normal range in 9 of the 22 patients (41\%), and was not below the normal range in any of the patients. Calcium was below the normal range in 1 of the 22 patients $(5 \%)$. Phosphorus was also below the normal range in 1 of the 22 patients $(5 \%)$. The ALP level was above the normal range in 12 of the 22 patients $(55 \%)$. N-PTH was above the normal range in 1 of the 22 patients $(5 \%)$, but was below the normal range in 11 patients (50\%; Fig 2).

The levels of ionized Ca, Ca, P, ALP, and N-PTH did not differ in relation to the postoperative period

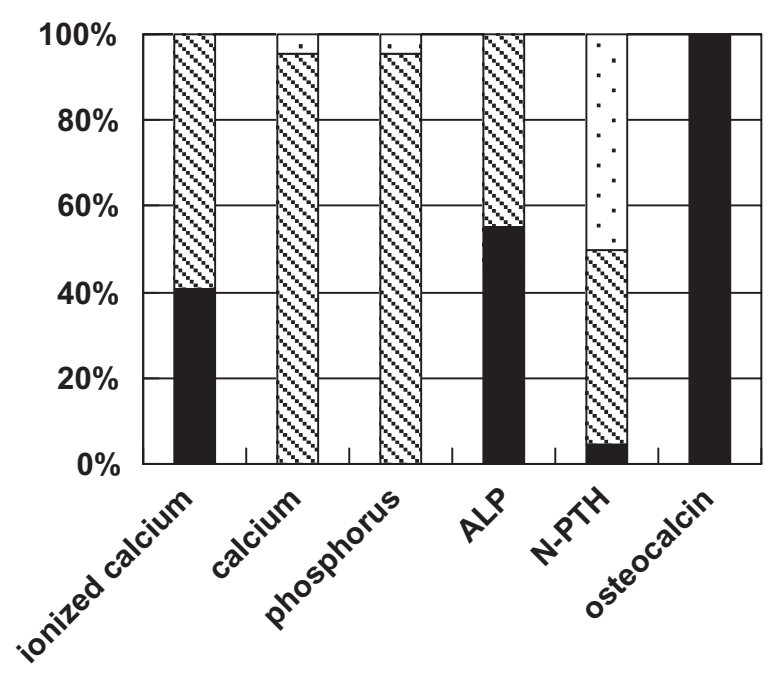

Fig. 2. Serum levels of ionized calcium, calcium, phosphorus, alkaline phosphatase $(A L P), \mathrm{N}$-parathyroid hormone $(N$ $P T H)$, and osteocalcin in gastrectomy patients. The serum level of ionized calcium was higher than the normal range in $9 / 22$ patients ( $41 \%$ ), and was not lower than the normal range in any of the patients. The serum calcium level was lower than the normal range in $1 / 22$ patients $(5 \%)$, and the serum phosphorus level was also lower than the normal range in $1 / 22$ patients $(5 \%)$. The serum ALP level was higher than the normal range in $12 / 22$ patients (55\%). The serum N-PTH level was higher than the normal range in $1 / 22$ patients $(5 \%)$, while it was lower than the normal range in $11 / 22$ patients $(50 \%)$. The serum osteocalcin level was higher than the normal range in all of the patients. White dotted bars, low level; striped bars, normal level; black bars, high level

or the type of gastrectomy procedure. The osteocalcin level was above the normal range in all of the patients.

On multivariate analyses, factors associated with the change in VD metabolites did not remain (Table 3 ). 
Table 3. Multivariate analysis (logistic regression) of differences in surgical procedures, passage of food through the duodenum, and postoperative period after gastrectomy

\begin{tabular}{|c|c|c|c|}
\hline Factor & Variable & Significance & Odds ratio \\
\hline \multicolumn{4}{|l|}{ Surgical procedure } \\
\hline & $25(\mathrm{OH}) \mathrm{VD}(\geqq 13 \mathrm{vs}<13 \mathrm{ng} / \mathrm{ml})$ & 0.855 & 9179.8 \\
\hline & $1,25(\mathrm{OH})_{2} \mathrm{VD} / 25(\mathrm{OH}) \mathrm{VD}(\geqq 3 \mathrm{vs}<3 \mathrm{ng} / \mathrm{ml})$ & 0.863 & 0.000 \\
\hline \multicolumn{3}{|l|}{ Duodenal passage } & 5000 \\
\hline & $1,25(\mathrm{OH})_{2} \mathrm{VD} / 25(\mathrm{OH}) \mathrm{VD}(\geqq 3 \mathrm{vs}<3 \mathrm{ng} / \mathrm{ml})$ & 0.251 & 0.278 \\
\hline \multicolumn{4}{|l|}{ Postoperative period } \\
\hline & $\begin{array}{l}25(\mathrm{OH}) \mathrm{VD}(\geqq 13 \mathrm{vs}<13 \mathrm{ng} / \mathrm{ml}) \\
1,25(\mathrm{OH})_{2} \mathrm{VD} / 25(\mathrm{OH}) \mathrm{VD}(\geqq 3 \mathrm{vs}<3 \mathrm{ng} / \mathrm{ml})\end{array}$ & $\begin{array}{l}0.289 \\
0.647\end{array}$ & $\begin{array}{l}0.262 \\
1.658\end{array}$ \\
\hline
\end{tabular}

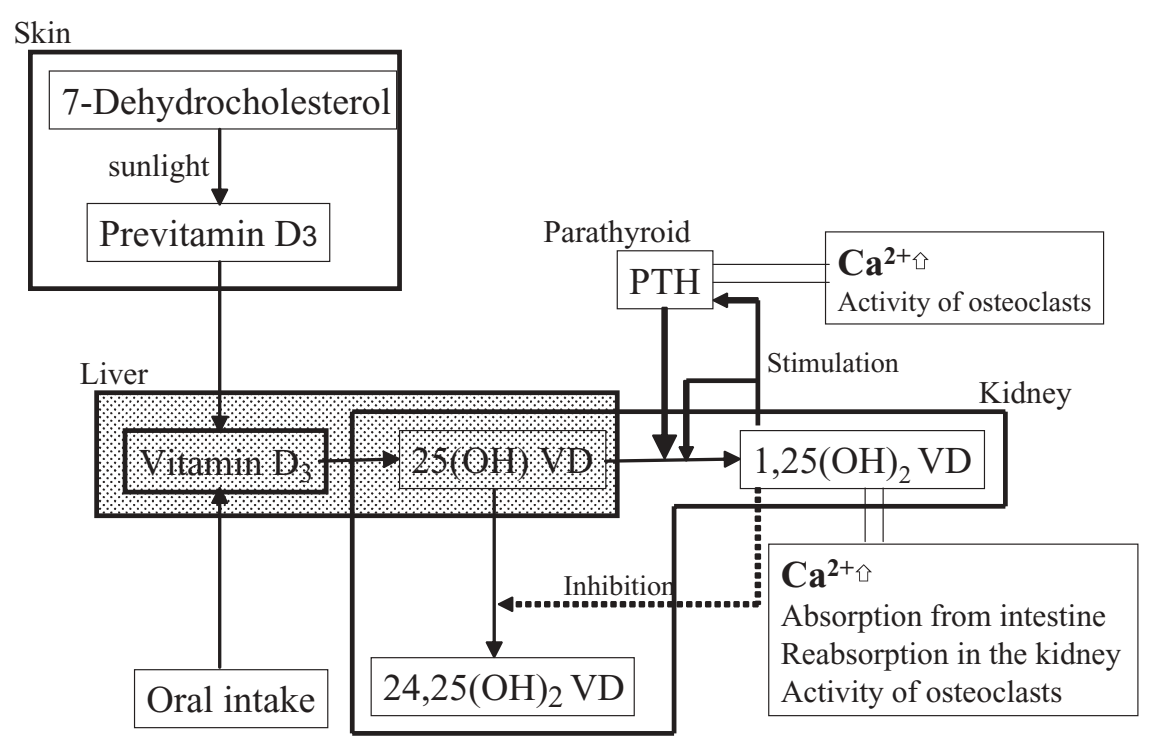

Fig. 3. Formation and hydroxylation of vitamin D3 and feedback control of $1,25(\mathrm{OH})_{2}$ VD. The formation of $25(\mathrm{OH}) \mathrm{VD}$ takes place in the liver, and the formation of $1,25(\mathrm{OH})_{2} \mathrm{VD}$ and $24,25(\mathrm{OH})_{2} \mathrm{VD}$ occurs in the kidneys. Feedback control participates in the formation of $1,25(\mathrm{OH})_{2} \mathrm{VD}$ and $24,25(\mathrm{OH})_{2} \mathrm{VD}$ from $25(\mathrm{OH}) \mathrm{VD}$ in the kidneys. Dashed arrow indicates inhibition, and thick solid arrows indicate stimulation

\section{Discussion}

An extensive number of reports have been published regarding the postoperative complications of gastrectomy for gastric cancer, including the dumping syndrome. Vitamin B12 malabsorption and bone disorders are also widely known post-gastrectomy complications [9], but intensive studies have not been performed and there are few reports with respect to changes in serum VD levels after gastrectomy. A number of investigators have reported that gastrectomy for gastric cancer leads to changes in bone metabolism and an increased risk of fracture [10-14].

We studied changes in circulating VD metabolites in patients who had undergone a gastrectomy for gastric cancer. Although a change in VD metabolism was observed, the increase in PTH that has been reported by other authors was not seen [6]. This suggests that post-gastrectomy bone disorders may progress slowly without an increase in $\mathrm{PTH}$, unlike the findings in hyperparathyroidism.
Figure 3 shows the formation and hydroxylation of VD [15]. The formation of 25(OH)VD takes place in the liver, and the formation of $1,25(\mathrm{OH})_{2} \mathrm{VD}$ occurs in the kidneys. In gastrectomized patients, food intake is reduced and malabsorption of fat occurs, and the formation of $25(\mathrm{OH}) \mathrm{VD}$ is reduced in the liver. However, the formation of $1,25(\mathrm{OH})_{2} \mathrm{VD}$ in the kidneys does not decrease to maintain the serum Ca level. In the present study, many patients showed a decrease in 25(OH)VD and $24,25(\mathrm{OH})_{2} \mathrm{VD}$, which are metabolites that show weak activity. This suggests that a homeostatic response maintains the normal level of $1,25(\mathrm{OH})_{2} \mathrm{VD}$, which is important in the regulation of $\mathrm{Ca}$.

Figure 4 shows the current understanding of $\mathrm{Ca}$ and bone metabolism after gastrectomy, according to the literature and our data. We guess that, because of the normal $1,25(\mathrm{OH})_{2} \mathrm{D}$ level in our patients, the pathway of $25(\mathrm{OH}) \mathrm{D}$ to $24,25(\mathrm{OH})_{2} \mathrm{D}$ was not stimulated and therefore PTH did not increase. However, in spite of the normal levels of $1,25(\mathrm{OH})_{2} \mathrm{D}$, the formation of $1,25(\mathrm{OH})_{2} \mathrm{D}$ was stimulated. Because of the gastrec- 


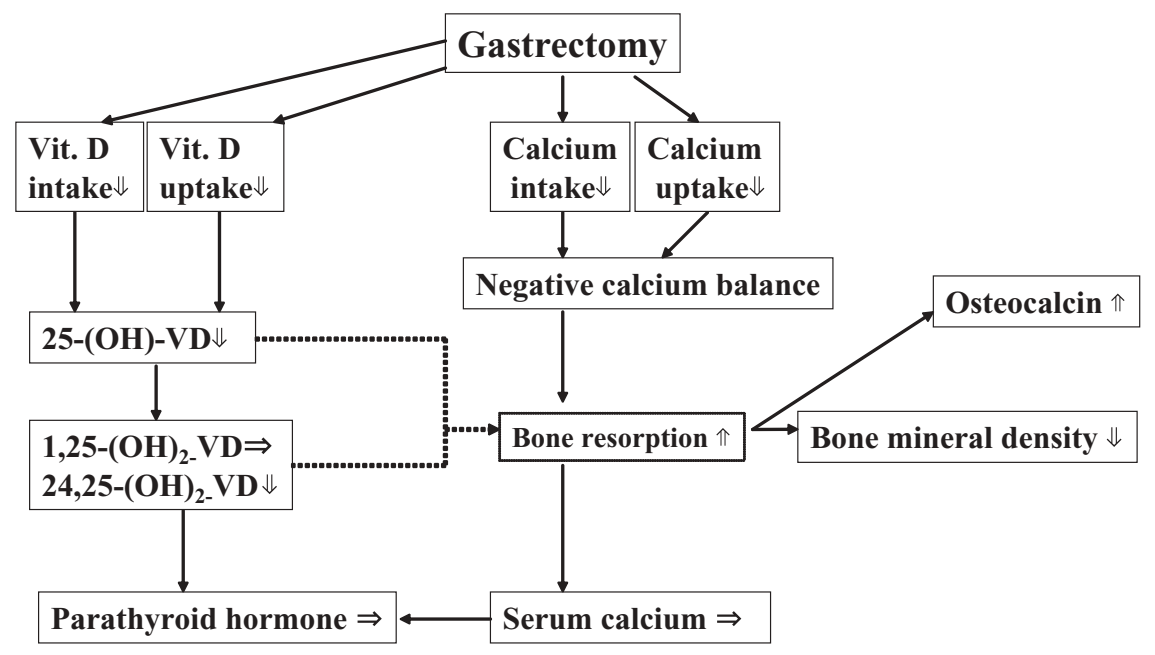

Fig. 4. Current understanding of calcium and bone metabolism after gastrectomy, according to the literature and our data. Dashed arrow shows that we have no idea how bone turnover is accelerated by the change in VD metabolites, but the accelerated formation of $1,25(\mathrm{OH})_{2} \mathrm{D}$ would probably stimulate bone turnover tomy, the decreased intake and absorption of Ca led to $\mathrm{Ca}$ insufficiency; bone turnover was accelerated and the osteocalcin level was elevated. The high level of osteocalcin, without high $1,25(\mathrm{OH})_{2} \mathrm{D}$ or PTH levels, showed acceleration of bone turnover induced by the change in VD metabolites. However, we have no idea how the bone turnover was accelerated by the change in VD metabolites; possibly, the accelerated formation of $1,25(\mathrm{OH})_{2} \mathrm{D}$ could have stimulated the bone turnover.

Thus, our findings suggested that gastrectomy had a moderate influence on the metabolism of VD. It was previously reported that no therapeutic response was obtained with $\mathrm{Ca}$ or VD supplements in postgastrectomy osteoporosis. [8] Nevertheless, it is reasonable to expect that bone metabolism could be improved by rectifying the changes in VD metabolism. Zittel et al. [6] reported that the serum $\mathrm{Ca}$ level was decreased, while the serum levels of Ca-regulating PTH and $1,25(\mathrm{OH})_{2} \mathrm{VD}$ were increased, in patients who had had a total gastrectomy compared with control subjects, and these changes were more prominent after a total gastrectomy than after subtotal gastrectomy. This is a different outcome to the result of our study, and may indicate the necessity for taking ethnic differences into consideration. However, our results showing a high $1,25(\mathrm{OH})_{2} \mathrm{VD} /$ $25(\mathrm{OH})$ VD ratio after a total gastrectomy, after gastrectomy procedures avoiding duodenal passage of food, and at 1 year or more postoperatively may indicate a high risk of bone fracture, as noted in the report of Zittel et al. [6].

There have been various reports regarding post-gastrectomy changes in $\mathrm{Ca}$ regulation. It was reported that the decrease in the serum Ca level was similar in patients with subtotal gastrectomy and those with total gastrectomy $[13,14]$. However, our patients showed virtually no decrease in serum $\mathrm{Ca}$ and maintained a serum ionized $\mathrm{Ca}$ level that was above the normal range. Free ionized $\mathrm{Ca}$ has an important role as a messenger in the blood coagulation response, muscle contraction, and nerve function [15], so our findings suggest that the amount of ionized $\mathrm{Ca}$ in gastrectomy patients is adequate to maintain normal biological functions.

In regard to the proportions of the three VD metabolites, a marked decrease in $25(\mathrm{OH}) \mathrm{VD}$ was found after a total gastrectomy and after procedures that allowed food to bypass the duodenum. This suggests that VD absorption may be severely disturbed in patients who undergo total gastrectomy or the Roux-en-Y reconstruction to treat gastric cancer.

Few reports are available regarding changes in the levels of other vitamins, such as lipid-soluble vitamin A, vitamin $\mathrm{E}$, and vitamin $\mathrm{K}$ after gastrectomy. However, it has been reported that the serum levels of vitamins A and $\mathrm{E}$ are decreased by a total gastrectomy [16, 17], and there is a report suggesting that vitamin $\mathrm{K}$ may also be decreased in patients who have had a total gastrectomy [16].

The administration of $1 \alpha$ results in activation of the metabolic pathway from $25(\mathrm{OH}) \mathrm{VD}$ to $24,25(\mathrm{OH})_{2} \mathrm{VD}$ and obviates the need for compensatory changes in VD metabolism that are needed to maintain a normal $1,25(\mathrm{OH})_{2} \mathrm{VD}$ level, such as the enhancement of the metabolic pathway from $25(\mathrm{OH}) \mathrm{VD}$ to $1,25(\mathrm{OH})_{2} \mathrm{VD}$ or the suppression of the pathway from $25(\mathrm{OH}) \mathrm{VD}$ to $24,25(\mathrm{OH})_{2} \mathrm{VD}$. Thus, normal VD metabolism can be restored by the use of $1 \alpha$.

\section{Conclusion}

Bone disorders following gastrectomy may occur because $\mathrm{Ca}$ and VD absorption are decreased due to a decrease in food intake, rather than because of a loss of hormone balance (including PTH) after gastric resection. Our results suggest that, after gastric resection, some VD metabolites decrease and bone disease devel- 
ops gradually, unlike the rapid bone changes caused by hyperparathyroidism. The administration of $1 \alpha$ seems to be effective for the treatment and prevention of bone disorders after gastrectomy for gastric cancer because it improves the balance of VD metabolites. To reach a definitive conclusion on this treatment, it will be necessary to examine a greater number of patients receiving $1 \alpha$ and to conduct additional assessments in the future.

\section{References}

1. Rino Y. Clinical study of the relationship between a metabolic bone disorder and an amount of daily food intake. Yokohama Med Bull 1996;47:25-9.

2. Tovey FI, Hall ML, Ell PJ, Hobsley M. A review of postgastrectomy bone disease. J Gastroenterol Hepatol 1992;7:639-45.

3. Alhava EM, Aukee S, Karjalainen P, Kettunen K, Juuti M. The influence of calcium and calcium + vitamin $\mathrm{D}_{2}$ treatment on bone mineral after partial gastrectomy. Scand J Gastroenterol 1975;10: 689-93.

4. Sharpe M, Noble S, Spencer CM. Alendronate. An update of its use in osteoporosis. Drugs 2001;61:999-1039.

5. Suzuki Y, Ishibashi Y, Omura N, Kawasaki N, Kashiwagi H, Yanaga $\mathrm{K}$, et al. Alendronate improves vitamin D-resistant osteopenia triggered by gastrectomy in patients with gastric cancer followed long term. J Gastrointest Surg 2005;9:955-60.

6. Zittel TT, Zeeb B, Maier GW, Kaizer GW, Zwirner M, Liebich H, et al. High prevalence of bone disorders after gastrectomy. Am J Surg 1997;174:431-8.

7. Rino $\mathrm{Y}$, Imada $\mathrm{T}$, Yamamoto $\mathrm{Y}$, Takahashi $\mathrm{M}$, Amano $\mathrm{T}$, Takanashi $Y$. The efficacy of $1 \alpha$ hydroxy vitamin $\mathrm{D}_{3}$ for treatment of the metabolic bone disorder in patients who underwent gas- trectomy for gastric cancer. Hepatogastroenterology 2000;47: 1498-500.

8. Tovey FI, Hall ML, Ell PJ, Hobsley M. Postgastrectomy osteoporosis. Br J Surg 1991;78:1335-7.

9. Kitajima M. Disorders after gastric surgery (in Japanese). In: Koyanagi H, Matsuno M, Kitajima M, Katoh H, editors. Standard Textbook of Surgery vol. 10. Tokyo: Igaku-Shoin; 2004. p. 577-9.

10. Rao SD, Kleerekoper M, Rogers M, Frame B, Parfitt AM. Is gastrectomy a risk factor for osteoporosis? In: Christiansen C, Arnand CD, Nordin BEC, et al., editors. Osteoporosis. Proceedings of the Copenhagen International Symposium on Osteoporosis, vol. 2. Ålborg: Ålborg Stiftsbogtrykkeri; 1982. p. 775-7.

11. Inoue K, Shiomi K, Higashide S, Kan N, Nio Y, Tobe T, et al. Metabolic bone disease following gastrectomy: assessment by dual energy X-ray absorptiometry. Br J Surg 1992;79:321-4.

12. Mellström D, Johansson C, Johnell O, Lindstedt G, Lundberg PA, Obrant K, et al. Osteoporosis, metabolic aberrations, and increased risk for vertebral fractures after partial gastrectomy. Calcif Tissue Int 1993;53:370-7.

13. Nilas L, Christiansen C, Christiansen J. Regulation of vitamin D and calcium metabolism after gastrectomy. Gut 1985;26:252-7.

14. Bisballe S, Eriksen EF, Melsen F, Mosekilde L, Sørensen OH, Hessov I. Osteopenia and osteomalacia after gastrectomy: interrelations between biochemical markers of bone remodeling, vitamin D metabolites, and bone histomorphometry. Gut 1991;32: 1303-7.

15. Bringhurst FR, Demay MB, Krane SM, Kronenberg HM. Bone and mineral metabolism in health and disease. In: Kasper DL, Braunwald E, Fauci AS, Hauser SL, Longo DL, Jameson JL, editors. Harrison's principles of internal medicine. 16th ed. New York: McGraw-Hill; 2005. p. 2238-49.

16. Adams JF. The clinical and metabolic consequences of total gastrectomy. III. Notes on metabolic functions, deficiency status, changes in intestinal histology, and radiology. Scand J Gastroenterol 1968;3:152-9.

17. Terashima M. Evaluation of nutrition in gastrectomy patients with long-term survival. J Jpn Soc Gastrointest Surg 1994;27: 1737-46. 